\title{
BOLIVIANOS EN ESPAÑA
}

POR

\section{MERCEDES FERNÁNDEZ GARCÍA}

Instituto Universitario de Estudios sobre Migraciones.

Universidad Pontificia Comillas

\begin{abstract}
El presente articulo tiene como objetivo analizar el comportamiento del colectivo boliviano en España, a partir de los microdatos de la Encuesta Nacional de Inmigrantes. Partiendo de los parámetros socioeconómicos de la integración y de los postulados teóricos del capital humano, del mercado de trabajo segmentado, y de la visión transnacional de las migraciones, y utilizando el análisis factorial de correspondencias múltiple se elabora un perfil de los bolivianos, que actualmente residen en España.

Palabras clave: Colectivo boliviano, integración socioeconómica, mercado de trabajo segmentado, exportabilidad del capital humano, transnacionalismo.
\end{abstract}

\section{INTRODUCCIÓN}

El colectivo boliviano ha sido hasta fechas muy recientes prácticamente desconocido en el mosaico migratorio español. Sin embargo, y casi de repente, a principios de 2008 representaba el $8 \%$ del total de extranjeros procedentes de países en desarrollo y el 5\% del total de extranjeros residentes en España. De hecho, desde Bolivia, nuestro país se ha configurado actualmente como destino preferido de los que deciden emigrar, por delante de los receptores tradicionales, Argentina y Estados Unidos.

El debilitamiento sostenido del desarrollo, la economía y la situación política de Bolivia son algunos de los factores determinantes del reciente éxodo; la elección de España como destino se debería principalmente al fácil acceso a nuestras fronteras y a las características de nuestro mercado de trabajo, con una vasta oferta de ocupaciones no cualificadas independiente, en muchos casos, del capital humano adquirido. 
Sin embargo, este statu quo ha comenzado a alterarse: de una parte se ha producido un endurecimiento de las condiciones que el gobierno de España ha impuesto a los ciudadanos bolivianos para la entrada en el país; de otra, todos los indicadores vienen anunciando (y confirmando) una crisis económica que tardará tiempo en resolver. Mientras tanto, la estructura de oportunidades de Bolivia no parece haber mejorado sustancialmente, con el consecuente entorpecimiento de virtuales retornos.

Dadas estas circunstancias parece de especial interés llevar a cabo un seguimiento objetivo y detallado de la situación de este colectivo entre nosotros y de sus perspectivas de futuro. Así, partiendo de los postulados de la visión transnacional de las migraciones, de las premisas existentes acerca de su integración socioeconómica y de las teorías del capital humano, se va a llevar a cabo un análisis cuantitativo de los datos que, sobre ciudadanos bolivianos, aporta la Encuesta Nacional de Inmigrantes.

El análisis se dividirá en dos partes: la primera abordará los dos aspectos más visibles de la integración socioeconómica de los inmigrantes, el trabajo y la vivienda; la segunda abundará en las relaciones con su lugar de origen: sus actividades transnacionales.

\section{MARCO CONCEPTUAL}

\section{La visión transnacional de las migraciones}

No es éste el momento de incidir en el complejo universo teórico que intenta, de alguna manera, explicar las migraciones ${ }^{1}$. Sin embargo, sí conviene indicar que, a lo largo del tiempo, la comunidad científica ha otorgado pesos e importancias muy diversos a las múltiples variables explicativas del fenómeno migratorio: dimensiones diferentes (económica, pero también política, social, cultural, etc.), pero también distintos niveles (transnacional, nacional y local), entendiendo estas esferas como interrelacionadas e interdependientes. Pues ignorar el contexto en el que se producen las migraciones, o centrarse sólo en una de sus dimensiones, puede tener graves consecuencias en el impacto que pretenden tener las acciones en este campo.

De hecho, en el momento actual la cuestión migratoria no puede entenderse sin hacer referencia al proceso de globalización (económica, informativa y del transporte) experimentado en el mundo en las últimas dos décadas. Las 1998.

1 Puede consultarse la pormenorizada aproximación realizada por Massey, D. S. et al., 
fronteras, entendidas a la manera tradicional de separación física, han desaparecido: los migrantes se trasladan a mucha mayor velocidad que en épocas pasadas; pero gracias a las telecomunicaciones, la distancia no es óbice para mantener los vínculos con el lugar de origen. Se crean así los denominados espacios transnacionales, caracterizados porque los individuos que los ocupan pertenecen simultáneamente a las sociedades de emisión y acogida ${ }^{2}$ y mantienen relaciones simultáneas y ramificadas que superan las fronteras geográficas, económicas, políticas, sociales y culturales ${ }^{3}$.

Especialmente relevantes resultan para este enfoque los análisis centrados en las redes migratorias ${ }^{4}$, en los que se incluyen los contextos de origen y destino, así como las interacciones entre ambos. La transferencia de información, valores, ideas, opiniones, dinero, tiene lugar a través de las nuevas tecnologías, que son su soporte técnico, pero también a través del capital social, es decir, del conjunto de relaciones personales y sociales que los migrantes van tejiendo y que vienen a constituir el soporte social de la transferencia. De esta forma, el capital social es usado para transferir el capital financiero, humano político y cultural por lo que juega un papel crucial a la hora de hablar de la reproducción de los campos sociales transnacionales, así como de crear identidades transnacionales y lealtades nacionales, regionales y locales. En este sentido resulta visionaria la obra pionera de M. Kearney, que ya en 1986 se refirió a la necesidad de usar unidades intermedias de análisis como «el grupo doméstico» y las «redes migratorias» $\rangle^{5}$. Recientemente, Faist habla del crucial meso-link al referirse a las redes de relación establecidas en los espacios transnacionales.

\section{Sobre la integración de los migrantes}

Acerca de la integración de los migrantes existen múltiples desarrollos teó$\operatorname{ricos}^{6}$, los cuales la consideran como aquel proceso a través del cual la población inmigrante adquiere la calidad de miembro participante activo en la so-

2 Faist, 2000.

3 Basch, Glick Schiller y Szanton Blanc, 1994.

4 Las redes migratorias tienen su anclaje en las teorías del capital social. Bourdieu y Wacquant, 1992, definen el mismo como «la suma de recursos, reales o virtuales, que un individuo o grupo acumula en virtud de la posesión de una red duradera de más o menos relaciones institucionalizadas de conocimiento mutuo y reconocimiento».

5 Kearney, 15 (Palo Alto, California, 1986): 331-361.

6 Adoptándose a los efectos de este artículo los propuestos inicialmente por Heckmann, 1999, y posteriormente por Borkert et al., 2007. 
ciedad, alcanzando un estatus y posición dentro de la misma en igualdad de oportunidades, sin que ello suponga la pérdida de la cultura de origen. Se refiere incluso al aprendizaje cognitivo-cultural y a los procesos de internalización que resultan necesarios para lograr una participación en la sociedad. En la esfera privada, dicha participación se refleja en las relaciones sociales y del grupo; la dimensión subjetiva de la misma puede observarse a través de los procesos de formación de la identidad étnica y nacional.

Este concepto de integración puede estructurarse a través de cuatro dimensiones: estructural, cognitivo-cultural, social e identitaria. $\mathrm{O}$, de manera más resumida ${ }^{7}$, legal, socioeconómica y religioso cultural. La primera y la segunda aparecen ligadas a las dimensiones estructural y social, e implican que la incorporación del inmigrante al nuevo contexto social se haga en condiciones tales que le permitan llevar una vida digna (esto es, no suponga un factor de pobreza o exclusión social; léase trabajo, vivienda, educación y salud). Y la segunda, vinculada a las dimensiones cognitivo-cultural e identitaria, consiste en que el inmigrante aúne y haga compatibles los dos contextos culturales: el de partida (como cultura propia) y el de destino (o cultura extraña que debe aprender y respetar). Se conformaría entonces el itinerario de migración, asentamiento e integración como un proceso de nueva cultura.

\section{El capital humano inmigrante y el mercado de trabajo segmentado}

A partir del concepto de integración que se ha manejado y, especialmente, haciendo alusión a su dimensión socioeconómica, la inserción laboral de los migrantes se configura tal vez como el factor más visible, por cuanto la migración es fundamentalmente económica. De hecho, el mercado de trabajo de las sociedades postindustriales, de las ciudades globales ${ }^{8}$, es dual, se encuentra fragmentado. En éstas los inmigrantes se insertan en estructuras de trabajo informal (como mano de obra flexible y de bajo coste), relacionadas con los procesos de hiperurbanización de las megalópolis ${ }^{9}$. En esta perspectiva no funcionarían las teorías del capital humano, que hacen depender las diferencias salariales de las capacidades adquiridas por el individuo ${ }^{10}$. De hecho, y así se ha

7 Así lo indican Pennix y Martiniello, 2004.

8 Sassen, 1999. Portes, 2000.

9 Ya lo anticipaba Piore en 1973, el principal factor de atracción de inmigrantes sería, en este contexto, la escasez de mano de obra nativa en determinados sectores productivos del país de destino.

10 El considerar a las capacidades humanas como bien económico fue algo ya intuido por Adam Smith en 1776 en su obra La riqueza de las naciones, aunque se desarrolló formalmente 
venido describiendo en multitud de ocasiones ${ }^{11}$, los inmigrantes que acceden a nuestro mercado de trabajo, se encuentran con grandes dificultades a la hora de rentabilizar su capital humano y, de hecho, experimentan una gran desvalorización profesional.

Una última cuestión interesante en la inserción laboral de los migrantes viene desde la sociología, desde de las redes sociales, vinculando el capital social como otra variable en el mercado de trabajo muy interrelacionada con el capital humano ${ }^{12}$. El acceso a los buenos puestos de trabajo no sólo depende de un buen nivel educativo sino también de la capacidad de mantener relaciones sociales por parte de la persona y de la calidad de éstas.

\section{El colectivo boliviano (en España)}

En el año 1998 había 1.249 bolivianos empadronados el país, mientras que 2008 (uno de enero) se ha llegado a 233.781 personas, ciento ochenta y siete veces más que hace una década. El colectivo boliviano representa hoy el $8 \%$ del total de extranjeros procedentes de países en desarrollo ${ }^{13}$, convirtiéndose, por su relevancia numérica y visibilidad, en la cuarta nacionalidad, tras los colectivos marroquí, ecuatoriano y colombiano. Con relación al total de la población extranjera, 5.520.577 individuos a la misma fecha, los bolivianos suponen un 5\%.

El crecimiento de la población boliviana en España es relativamente suave hasta el año 2003 y desde entonces aumenta a ritmo exponencial. Se trata de una migración que, desde sus inicios, presenta una marcada y mantenida feminización (56\% de mujeres durante toda la década) y con una relativa concentración geográfica, pues la mitad de los efectivos se distribuyen entre Cataluña y la Comunidad de Madrid. Casi el 87\% de los bolivianos empadronados tiene edades comprendidas entre los 15 y los 65 años, lo cual lleva a suponer que la migración boliviana es fundamentalmente económica. El 29\% es natural de Cochabamba, el 37\% procede de Santa Fe, el 12\% de La Paz y el resto se distribuye en otras provincias.

Tradicionalmente los bolivianos han tenido dos lugares de inmigración ${ }^{14}$ : Argentina fue destino de familias bolivianas durante las décadas de los ochen-

en el siglo XX, a partir de la década de los sesenta, por autores como Schultz, 1961, y Mincer, 1974, entre otros.

11 Cachón, 2004. Tornos, Aparicio y Fernández, 2004. Argerey et al., 2005.

12 Vertovec, 2003.

13 Y debe notarse que España es el segundo destino de emigración para los bolivianos después de Argentina: según estimaciones del CEBEC, nuestro país acoge al 15\% de la población que reside fuera del país.

14 Whitessell, 2008. CEBEC, 2007. 
ta y noventa del pasado siglo, hasta que este país comenzó con su última crisis económica. Se trataba de una migración liderada por el cabeza de familia con relativamente bajo coste personal y alto grado de adaptación. Las estimaciones más recientes cifran en un 43\% el número de bolivianos emigrados a Argentina Por su parte, Estados Unidos ha sido lugar de atracción durante el último medio siglo, albergando actualmente al $15 \%$ de los emigrantes bolivianos; los requisitos de visado y las dificultades del idioma, no obstante, han jugado en los últimos tiempos como factores disuasorios.

De hecho, la conjunción de las circunstancias de la Argentina y los Estados Unidos ha ocasionado que España, país que hasta mediados de 2007 no exigía visado para la entrada de ciudadanos de Bolivia, sea aún en la actualidad el destino preferido de éstos. La contrapartida más tangible sería la cifra de remesas recibidas que, en el año 2007 (951 millones de dólares), supuso ni más ni menos que el 10\% del PIB boliviano. A fecha de hoy Bolivia es, según datos del Banco de España, el responsable del 12\% del total de envíos al extranjero desde nuestro país, sólo por detrás de Ecuador y Colombia.

\section{Metodología Seguida En Este trabajo}

El presente análisis del colectivo boliviano en España se ha llevado a cabo a partir de dos fuentes:

La primera, el Estudio sobre la situación de la inmigración boliviana en España realizado por el Instituto Universitario de Estudios sobre Migraciones por encargo del Observatorio Permanente de la Inmigración. Este estudio, consistente en el análisis de una encuesta realizada a cuatrocientos bolivianos en las provincias de Madrid, Barcelona y Valencia, será próximamente publicado. Aunque no es factible difundir de momento los resultados de este análisis, el conocimiento que, a partir del mismo, se obtuvo, ha servido para enfocar y estructurar el análisis que se lleva a cabo en el presente trabajo.

La segunda es la Encuesta Nacional de Inmigrantes (ENI) que el Instituto Nacional de Estadística (INE) realizó en el año 2007 a 15.500 inmigrantes, 460 de ellos bolivianos. Su principal objetivo es proporcionar información sobre las características sociodemográficas de los nacidos en el extranjero y relativas al establecimiento e importancia que la composición del grupo familiar tiene en las decisiones y estrategias del fenómeno migratorio. Estudia diferentes tipos de variables: sociodemográficas de los nacidos en el extranjero, composición y características del hogar y la vivienda, condiciones en el país de partida, experiencia migratoria y medios utilizados para la llegada a España, variaciones residenciales y laborales en España. 
En las páginas siguientes se lleva a cabo un análisis de los microdatos de la ENI centrado en las dos cuestiones básicas que afectan a todos los colectivos migrantes, de las que ya hemos dado cuenta en nuestro breve marco conceptual: la inserción en el entorno (léase integración, particularmente en su ámbito socioeconómico) y las relaciones con sus lugares de origen (redes transnacionales). Múltiples factores interaccionan en este análisis, por lo que se ha recurrido a la estadística multivariable; concretamente a las técnicas de interdependencias y, dentro de éstas, al análisis factorial de correspondencias múltiple. Esta técnica es una extensión del análisis de correspondencias simple -ideado inicialmente por Benzécri y posteriormente tratado por múltiples autore $^{15}$ - que permite estudiar las relaciones entre variables categóricas o cualitativas; es decir, no métricas. Esta técnica no sólo analiza la relación existente entre las variables, sino que permite conocer cómo está estructurada esta relación a través de la representación simultánea de las mismas en un espacio vectorial de dos, tres o más dimensiones. De este modo, una proximidad en el espacio de dos o más categorías de una misma variable implicará que ambas se comportan de manera similar (pudiendo incluso ser combinadas). La proximidad entre variables o categorías diferentes indicará asociación o similitud entre las mismas. Un alejamiento entre ellas supone justo lo contrario ${ }^{16}$.

\section{LA INTEGRACIÓN SOCIOECONÓMICA DE LOS BOLIVIANOS}

Acerca de las cuestiones que afectan a esta dimensión de la integración de los bolivianos atendemos, en principio, aquellas que de manera más visible se configuran, siendo, por ello, las que más fácilmente pueden analizarse partiendo de datos de índole cuantitativa. Nos referimos concretamente a los ámbitos del trabajo y de la vivienda de los inmigrantes.

\section{El mundo del trabajo}

Capital humano, sector de ocupación, calidad del puesto de trabajo y procedencia geográfica. Diferencias entre España y Bolivia

En Bolivia se da una clara segmentación sectorial del mercado de trabajo, más de las tres cuartas partes de los encuestados se encuentran ocupados entre

15 Greenacre, 2008.

$16 \mathrm{Si}$, por ejemplo, se representa conjuntamente el sector de ocupación, el tiempo de estancia en España, el nivel de estudios y el salario, puede que encontremos que el tiempo de estancia y el sector de ocupación son capaces de discriminar entre los trabajadores, pero no así el nivel de estudios. También puede encontrarse que dos sectores profesionales se comportan de manera parecida entre sí. 
la industria (29\%), el comercio $(22 \%)$ y los servicios $(26 \%)^{17}$ (excluyendo hostelería y servicio doméstico). El 45\% declara desempeñar puestos de nivel alto (directivos y profesionales cualificados) o medio alto (técnicos de apoyo y administrativos). Por su parte, el capital humano, léase cualificación académica, se distribuye de manera desigual: la cuarta parte de los encuestados apenas alcanza los estudios primarios y no llega al $15 \%$ el número con estudios universitarios (de primero o segundo ciclo); la mayoría, pues, posee estudios secundarios. La distribución geográfica del capital humano es también relevante: de los que vienen de Cochabamba casi un tercio declara estudios primarios (o inferiores), mientras que de los de La Paz, un cuarto presenta estudios universitarios. Estudios primarios posee un cuarto de los de Santa Fe, y estudios secundarios casi el $70 \%$.

Un análisis conjunto de estas variables permitirá establecer relaciones entre el capital humano, marcado por el nivel de estudios, el sector de actividad, la calidad de la ocupación y el lugar del país de donde los bolivianos proceden. Puestos de alta y media cualificación se vinculan a estudios superiores y al sector servicios, siendo el comercio (categoría media-baja) y la industria (baja) de índole inferior y relacionándose con los estudios secundarios y primarios. La cuestión geográfica es también relevante: los puestos más bajos, vinculados con la industria y los estudios básicos proliferan en mayor medida en Cochabamba y luego en Santa Cruz; este último lugar se caracteriza por albergar puestos de trabajo en el comercio para individuos con estudios secundarios. Se corrobora así la fragmentación geográfica, sectorial y por estudios en el mercado laboral de origen ${ }^{18}$.

Parangonando esta situación con la de España se detecta cierto paralelismo, aunque el centro de gravedad resulta ser más precario ${ }^{19}$ : sólo un $4 \%$ de los trabajadores bolivianos declara desempeñar ocupaciones de cualificación alta

17 Se excluyen del mismo las actividades intensivas en mano de obra y que aportan escaso valor añadido como la hostelería o el servicio doméstico y se eliminan las referencias a las actividades comerciales. Nos referimos, por tanto, al transporte, las comunicaciones, actividades empresariales, inmobiliarias, sanidad y educación.

18 La relación positiva entre la renta per capita y el capital humano aparece también constatada en el mencionado estudio del CEBEC.

19 A 31 de diciembre de 2007 existían 50.580 afiliados a la Seguridad Social, distribuidos entre los servicios $(65 \%)$, construcción $(22 \%)$, agricultura $(7 \%)$ e industria $(6 \%)$. Esta cifra es muy baja comparada con el número de empadronados en edad de trabajar, ello implica la existencia de un elevado porcentaje de trabajadores en la economía sumergida: una aproximación grosera permite deducir que el $71 \%$ de los individuos se encontraría en situación irregular. Este hecho implica una gran precarización del trabajo de este colectivo. 
o siquiera media alta; un $25 \%$ se autositúa en el estrato medio bajo y el $71 \%$, casi tres cuartos de la muestra, en el bajo.

Gráfico 1. Mercado de trabajo boliviano y mercado de trabajo español. Calidad de LAS OCUPACIONES, SECTORES, NIVEL DE ESTUDIOS.
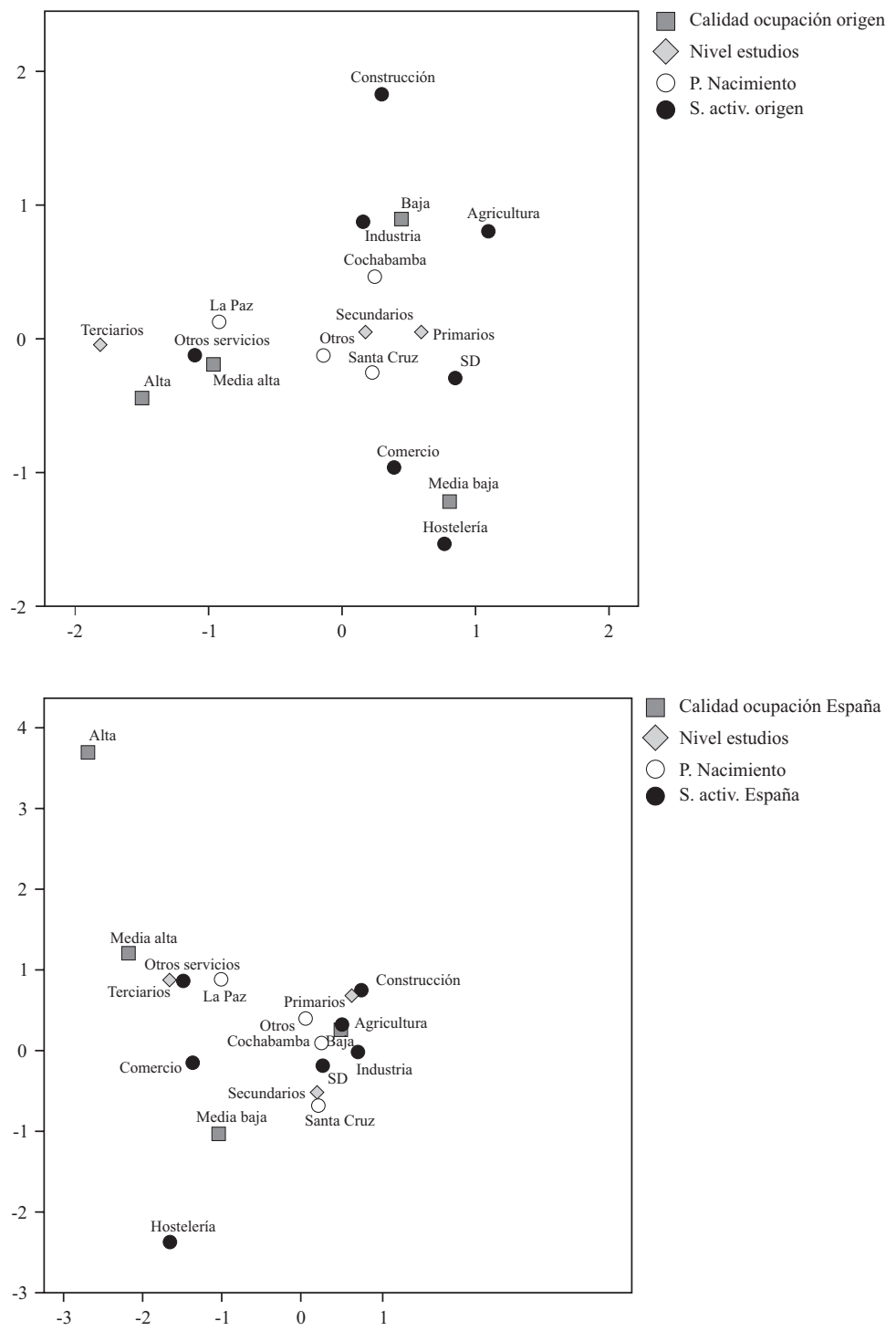

Calidad ocupación España

$\triangle$ Nivel estudios

P. Nacimiento

S. activ. España

Fuente: Elaboración propia a partir de los microdatos de la ENI. 
Además se dibujan tres nichos de trabajo boliviano: servicio doméstico (este antonomasia con el 48\% de encuestados), construcción (17\%) y otros servicios $(12 \%)^{20}$.

En cuanto a las otras dos variables, el nivel de estudios y el lugar de procedencia en Bolivia, se ve como, de una parte, el servicio doméstico y la construcción aparecen ligados (además de a categorías laborales inferiores) a los estudios primarios y secundarios y a los originarios de Santa Cruz y Cochabamba, mientras que el tercero de los nichos, el resto de los servicios, se vincula a los estudios terciarios, a categorías profesionales de mayor reconocimiento y a los naturales de La Paz.

Aunque no puede olvidarse que el servicio doméstico es relevante en todos los casos al acoger a un 45\% de los de Cochabamba, un 44\% de los de La Paz y un $48 \%$ de los de Santa Cruz. Por este mismo orden, la construcción alberga al $21 \%, 13 \%$ y $15 \%$ respectivamente y los otros servicios al $11 \%, 22 \%$ y $12 \%$. Por terminar de describir esta situación, si es cotejan sectores y cualificación profesional en los lugares de origen y destino y hacemos ahora un desdoblamiento en función del sexo, podemos obtener una conclusión clara de la evolución laboral entre origen y destino sufrida por los bolivianos.

El sector de los otros servicios (recuérdese empresariales, inmobiliarios, transporte, etc.), aunque en España ofrece puestos de categoría media baja es el que atrae a aquellos que en su lugar de origen desempeñaban puestos parecidos, aunque de mayor calidad. Por otra parte la construcción ha resultado ser hasta el momento el nicho en el cual el capital humano es más exportable, en cuanto que acoge a las dos terceras partes de los individuos que en su país trabajaban en el sector.

Con el servicio doméstico sucede justamente lo contrario, en él recaban personas con experiencias profesionales muy diversas (el 62\% de los que en su país se dedicaban a la hostelería, el 57\% de los que estaban en el comercio y el $49 \%$ de los trabajadores de la industria) y se configura como la verdadera puerta de entrada de trabajadoras bolivianas en España ${ }^{21}$.

20 No se debe, sin embargo, obviar que se está analizando una encuesta y, por ello, datos referidos a determinado momento y circunstancias. Las conclusiones de este análisis podrían, por ello, permitir inferir el futuro sólo en el supuesto ceteris paribus. Aquí posiblemente se encuentra el mayor problema de cualquier análisis exhaustivo de la ENI: que ésta se ha llevado a cabo en el momento del tiempo que marca el final de la fase de crecimiento de la economía española y por tanto en el momento del tiempo en el que se produce un cambio importante en el mercado de trabajo inmigrante.

21 La segmentación por sexo del mercado de trabajo inmigrante boliviano aparece también estudiada en otros entornos, por ejemplo, según el estudio monográfico realizado por Bastia, 2007, en el caso de Argentina, el servicio doméstico y el sector textil se configuran como nichos específicos para las mujeres bolivianas. 
De hecho, la palmaria fragmentación por sexo que sufre el mercado de trabajo inmigrante español ocasiona que el gráfico se divida claramente en dos partes quedando a la derecha los nichos masculinos, agricultura, industria y (especialmente) construcción y a la izquierda los femeninos, el servicio doméstico y los otros servicios.

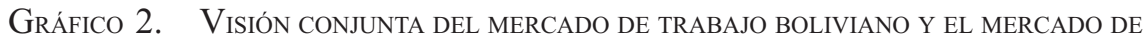
trabajo español. CALidAd de las ocupaciones, Sectores, SEXo.

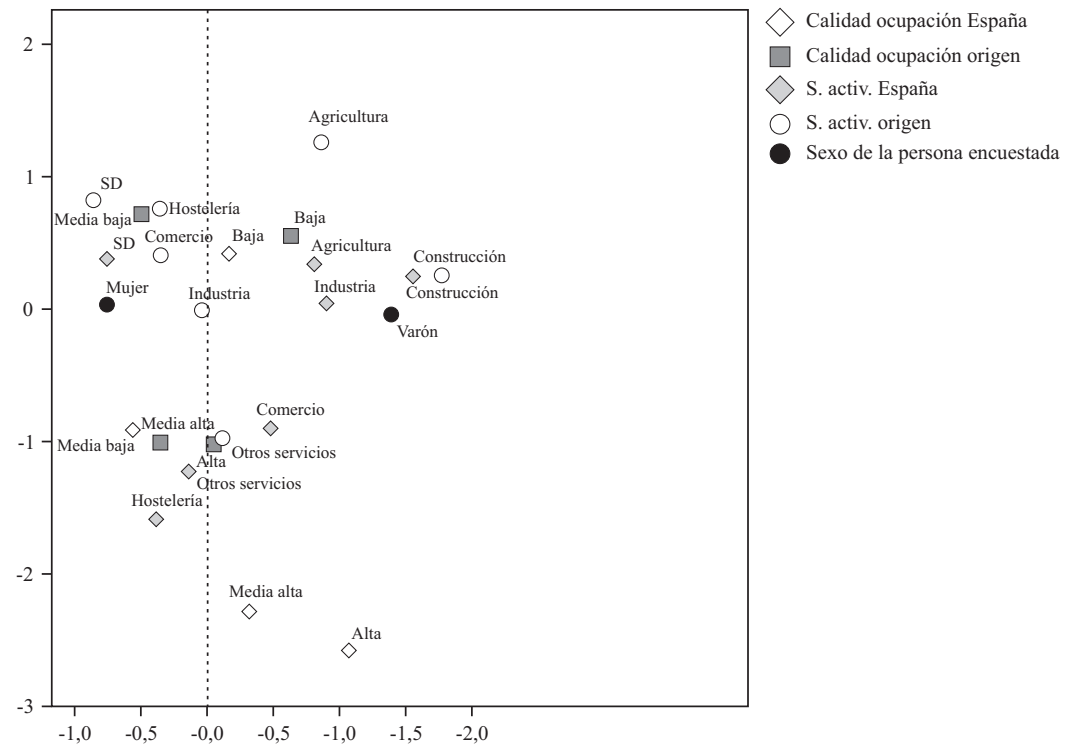

Fuente: Elaboración propia a partir de los microdatos de la ENI.

Bástenos decir que el $47 \%$ de los encuestados varones se dedica a la construcción, el $16 \%$ a la industria y el 14\% a la agricultura. Mientras que las mujeres se dividen entre el servicio doméstico (72\%) y los otros servicios (13\%).

Algunas variables determinantes de la (tímida) movilidad social ascendente: el nivel de estudios y (sobre todo) el paso del tiempo

Hasta el momento se ha venido hablando de nichos laborales y, de paso, se han hecho indicaciones acerca de posibles vías de entrada existentes en el mercado de trabajo español. Ello nos lleva a plantear la posibilidad de que se dé cierto dinamismo, cierta permeabilidad, cierta movilidad. Se analiza a conti- 
nuación este aspecto contemplando de manera conjunta dos variables cuyas virtualidades en la movilidad laboral ascendente pueden ser consideradas positivas: el paso del tiempo y el capital humano aportado.

En el gráfico 2 se exponen las relaciones existentes entre el tiempo de estancia, el sector de ocupación, el salario mensual y la cualificación académica. Se contempla con claridad cómo existe una relación positiva y creciente entre el tiempo de estancia en España y el monto salarial; y cómo existe, también, clara conexión entre las remuneraciones percibidas y el sector de actividad. Por lo que respecta al nivel de estudios también se percibe la asociación de altos niveles de capital humano con salarios más elevados, aunque aquí debe destacarse que la significatividad estadística es más débili22.

Para llevar a cabo el análisis se ha dividido el gráfico 2 en tres partes. Cabe detenerse a analizar, en primer lugar, el apartado de la izquierda, que claramente asocia bajos niveles de estudios, escaso tiempo de estancia, bajos salarios con un determinado sector de ocupación, el servicio doméstico. De hecho es de reseñar cómo la mitad de los encuestados que llevan menos de un año en el país declaró ganar menos de 700 euros, encontrándose el 57\% en el mencionado sector; en cuanto al nivel de estudios, un 30\% de sus integrantes poseen estudios primarios y un $60 \%$ secundarios.

La parte central del gráfico 2 explicaría la situación de los que llevan un tiempo intermedio en España, entre tres y cinco años, que han conseguido unos salarios mayores, y cuya localización dentro del mercado de trabajo español comienza a desvincularse del servicio doméstico y a derivar hacia otros sectores de mayor reconocimiento social. Así, casi un tercio de los que llevan en España entre tres y cinco años gana entre 700 y 900 euros y otro tercio entre los 900 y los 1.300. Aunque el servicio doméstico continúa teniendo importancia en este segmento, ahora son el $45 \%$ los encuestados incluidos en el mismo, se observa el despegue de la categoría otros servicios, que ocupa a un $14 \%$ de los encuestados; un 16\% están en la construcción y un 7\% en la industria. En cuanto al tema del capital humano la construcción se nutre principalmente de sujetos con estudios primarios (31\%) y secundarios $(57 \%)$, la industria presenta patrones parecidos $(25 \%$ de primarios y $71 \%$ secundarios $)$ y el sector otros servicios destaca por el alto porcentaje de universitarios, más de un tercio de sus integrantes.

22 Debido fundamentalmente a que no existe una clara relación entre el año de llegada y el nivel de estudios y ello implica que individuos con elevado bagaje académico, recién venidos a España, puedan encontrarse en la situación de aceptar cualquier cosa a la espera de ir progresando. 
Gráfico 3. Mercado de trabajo español. Remuneración del capital humano y paso DEL TIEMPO.

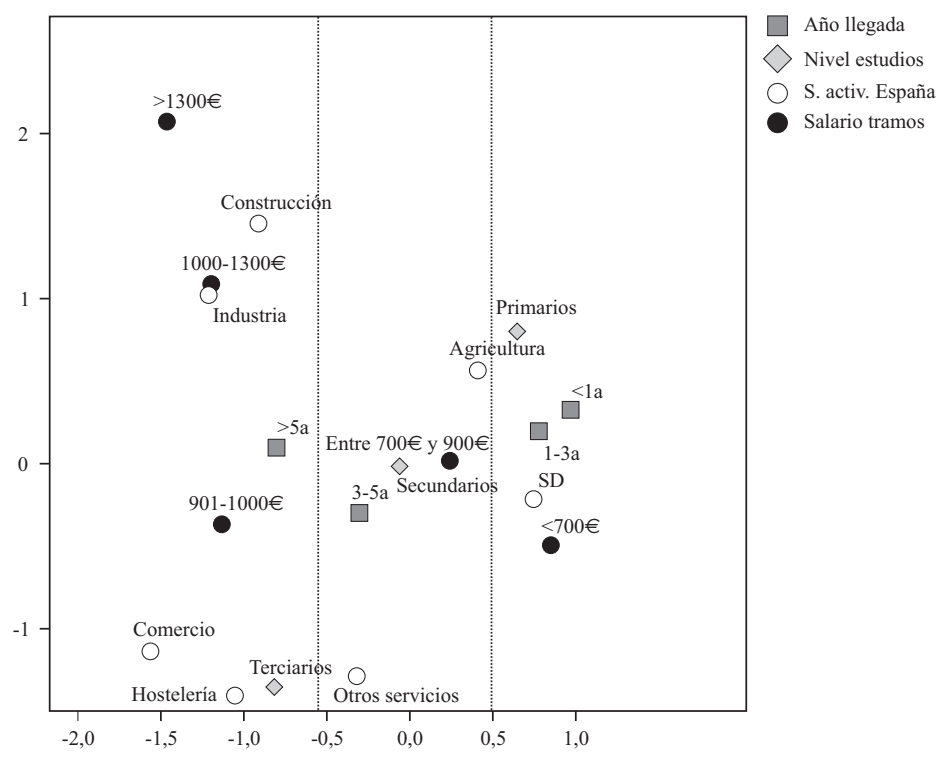

Fuente: Elaboración propia a partir de los microdatos de la ENI.

Por último, se analiza aquella parte del gráfico vinculada en mayor medida a aquellos que llevan en España un lapso de tiempo importante, más de cinco años. Esta sección viene vinculada a los más altos niveles salariales y a sectores en los que (dentro de las limitaciones que ya hemos puesto de relieve) bien se goza de mayor reconocimiento social (comercio, otros servicios), bien las remuneraciones son importantes. Del grupo que lleva más de cinco años en España, el $40 \%$ percibe remuneraciones comprendidas entre los 900 y los 1.300 euros y un 7\% supera este último monto. La ubicación sectorial se diversifica, encontrándose un $18 \%$ en la construcción, el $15 \%$ en la industria, el $14 \%$ en otros servicios y el $8 \%$ en el comercio; el servicio doméstico continúa perdiendo posiciones, aunque aún acoge a un nada despreciable $36 \%$ de los encuestados. El 38\% de los encuestados que trabajan en el comercio posee estudios universitarios. 


\section{Usos del hábitat}

\section{La precariedad residencial y la situación laboral}

Lo que primero llama la atención al analizar las pautas de uso de la vivienda del colectivo boliviano es la precariedad residencial: Un 84\% de la población vive entre la vivienda alquilada (muchas de ellas por habitaciones) o el domicilio del empleador. El régimen de propiedad es el más raro, debiéndose, además, destacar que, conjuntamente con la modalidad cesión de uso, no llega al 15\% el número de individuos en estas circunstancias.

Indudablemente la situación laboral de los individuos tiene mucho que ver con los usos del hábitat, especialmente cuando se recuerda el elevado porcentaje de mujeres que, en un mercado de trabajo muy segmentado en función del sexo, ocupan el nicho del servicio doméstico. Así los datos de la encuesta nos indican que mientras un $80 \%$ de los hombres vive en situación de alquiler o asimilado, un tercio de las mujeres lo hace en el domicilio del empleador. No obstante esta situación se normaliza con el paso del tiempo, pues de entre los que llevan en España menos de un año, esta es la manera de vivir para casi la mitad de las encuestadas; sin embargo de entre las que llevan mas de cinco años apenas un $12 \%$ se encuentra en ésta circunstancia destacando un $16 \%$ de propietarias.

GrÁFICO 4. RÉGIMEN DE TENENCIA DE LA VIVIENDA.

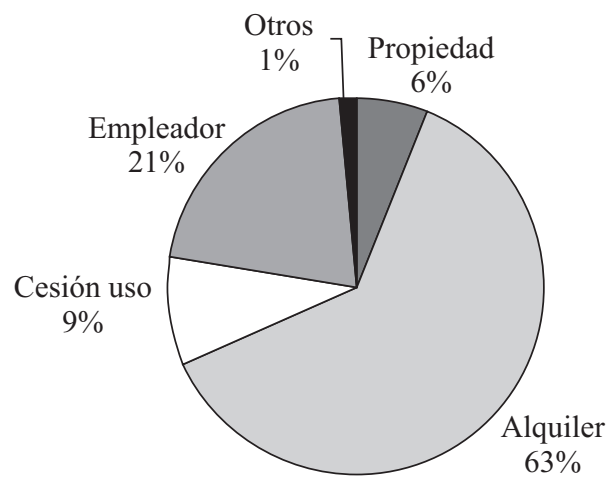

Fuente: Elaboración propia a partir de los microdatos de la ENI.

En cuanto a los varones, los que llevan menos de un año viven en un $80 \%$ en régimen de alquiler y un $11 \%$ en el domicilio del empleador. Para los que 
llevan más de cinco años, el porcentaje de los residentes en casa del patrón desciende hasta el $8 \%$ y el número de propietarios es del $22 \%{ }^{23}$.

Situación familiar y paso del tiempo: evolución de las pautas residenciales del colectivo boliviano

Al igual que se hizo para el mercado de trabajo, en el ámbito de la vivienda se ha evaluado la variable «tiempo de estancia en España» como determinante de al menos dos aspectos: la situación familiar del encuestado y el régimen de tenencia de la vivienda. Además se incluyen como variables de análisis la provincia de nacimiento del encuestado y el número de integrantes de la vivienda.

Conviene aquí remarcar de nuevo que el régimen de tenencia por antonomasia dentro del colectivo boliviano es el alquiler (modo en el que se encuentra el $61 \%$ de los encuestados). Además, es oportuno indicar que una parte importante de los encuestados, el $40 \%$, vive con parientes consanguíneos, que van desde el cónyuge y los hijos hasta los hermanos o los abuelos, lo que podríamos decir familia nuclear. Otra parte importante, un 30\%, comparte su vivienda con parientes y no parientes, lo cual implica un medio más perentorio de asentamiento; aunque, en todo caso, destaca la fuerte presencia que el parentesco tiene para el colectivo boliviano. De hecho un nada despreciable $11 \%$ vive con la familia extensa, esto es, consanguíneos y parientes no consanguíneos. Los que viven en el domicilio del empleador son casi un quinto del total.

Desagregando ahora estas dos variables por provincia de nacimiento del encuestado vemos como los naturales de Cochabamba presentan una pauta de establecimiento menos firme, más de la mitad vive, bien con el empleador $(24 \%)$, o bien con parientes lejanos y otros paisanos (30\%); dicho de otra manera, se trata de vías menos estables de asentamiento familiar. Tan sólo un tercio vive con su familia. Por lo contrario destacan los de Santa Cruz que declaran en un $50 \%$ vivir con consanguíneos, aunque otra pauta también importante es el modo familia y amigos que abarca al $27 \%$ de los oriundos de este lugar; por último destaca el escaso peso que para ellos posee el domicilio del empleador, que tan sólo alberga al $10 \%$ de los efectivos ${ }^{24}$. En cuanto a los paceños, unas dos quintas partes viven con su familia y un tercio con el empleador.

23 No obstante hay que indicar que los que llevan más de cinco años en España son muy pocos, no llegan al $24 \%$ de los encuestados.

24 Asumiendo que un $48 \%$ de los oriundos de Santa Cruz trabajan en el sector del servicio doméstico, todo lleva a pensar que están «echando horas», no como servicio interno. Ello tiene indudablemente que ver con su antigüedad en España, pues un $66 \%$ de los encuestados procedentes de este lugar lleva entre nosotros más de tres años. 
El año de llegada se configura, por otra parte, como determinante de las pautas habitacionales: el 91\% de los que llevan menos de un año están en régimen de alquiler o bien con el empleador; de hecho la mitad de este colectivo declara vivir de manera conjunta con parientes y paisanos. Para los que llevan tiempo en España, más de tres o más de cinco años, sin embargo, desciende de modo drástico la estancia en el domicilio del patrón y existen cotas relativamente discretas de propietarios (4\% para los que lo han hecho más de tres, casi un quinto de los que llevan más de cinco) o de individuos que habitan viviendas cedidas por otros (el $10 \%$ de los que llevan de tres años en adelante en España posee esta modalidad). Por otra parte, el hecho de que entre los más asentados familiarmente se esté dando esta modalidad de tenencia puede ser indicativo de la estructuración y fortalecimiento de las redes familiares. La manera de vivir es también muy diferente, pues el 44\% de los que llevan en España entre tres y cinco años y el 65\% de aquellos con antigüedad superior a los cinco habitan con sus consanguíneos.

Gráfico 5. RÉGIMEN DE TENENCIA DE LA VIVIENDA, SITUACIÓN FAMILIAR, PASO DEL TIEMPO.

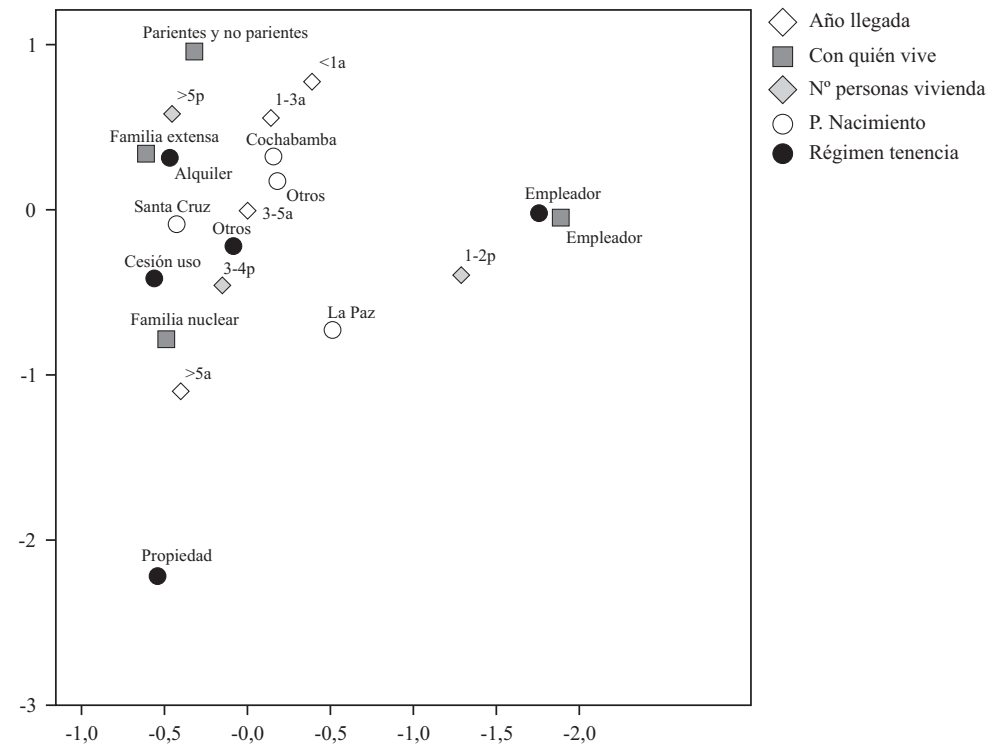

Fuente: Elaboración propia a partir de los microdatos de la ENI.

Además existe relación clara entre el número de integrantes de la vivienda, la situación familiar del encuestado y el régimen de tenencia. Habitualmente en el domicilio del empleador hay un menor número de personas (una o dos en el $56 \%$ de los casos), mientras que si se convive con la familia extensa o paisa- 
nos, el número de individuos por vivienda es superior a cinco entre el $60 \mathrm{y} \mathrm{el}$ $70 \%$ de los casos. El tamaño de la familia consanguínea ronda las tres o cuatro personas en la mitad de las observaciones.

Para finalizar el apartado, se intenta establecer alguna relación entre el régimen de tenencia de la vivienda y el nivel de ingresos percibido por los migrantes. Esta relación es más débil que las anteriormente analizadas, lo cual se detecta por la proximidad de todas las variables dentro del gráfico y su cercanía al origen de coordenadas. A pesar de ello sí se observa cómo a menores niveles salariales la situación residencial se escora hacia pautas más precarias. Así, de aquellos cuyo salario es inferior a los 900 euros, un tercio vive con el empleador y un $60 \%$ lo hace de alquiler. Por el contrario, entre los que ganan más de mil euros mensuales el $20 \%$ se reparten entre propietarios y usuarios por cesión de las viviendas. Además, el régimen de tenencia se revela consecuencia de las situaciones laborales que mostraban los encuestados en función de su procedencia geográfica: Entre los paceños se encuentra el mayor número de propietarios (un $13 \%$ de los mismos lo son); sin embargo la mayor parte de los cochabambinos se encuentran entre el domicilio del empleador (26\%) y el alquiler (64\%). Los santacruceños se encuentran entre el alquiler (67\%) y la cesión de uso (15\%), categoría esta última asociada a la convivencia con familiares directos.

GrÁfico 6. RÉGIMEN de teNENCIA DE LA VIVIENDA, PROVINCIA DE ORIGEN, NIVEL DE INGRESOS.

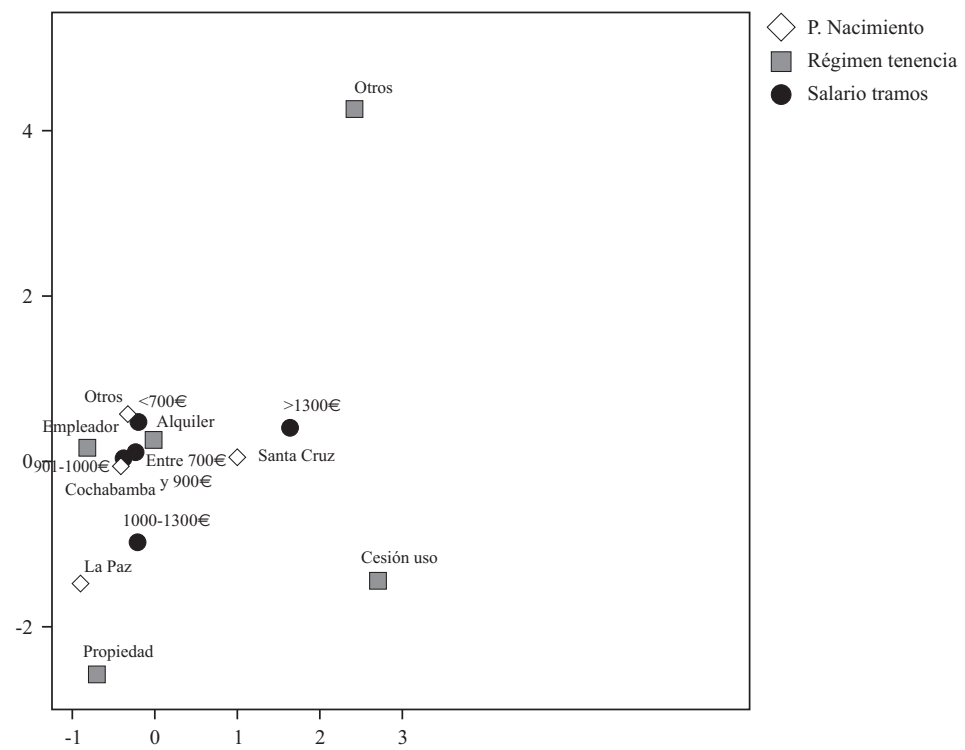

Fuente: Elaboración propia a partir de los microdatos de la ENI. 


\section{REDES INCIPIENTES Y DEBILIDAD EN LAS ACTUACIONES TRANSNACIONALES}

\section{Historia migratoria y contacto con su lugar de origen}

El análisis acerca de las pautas residenciales de los bolivianos ha permitido conocer la tendencia a compartir la vivienda con la familia nuclear o extensa (más de la mitad lo hacen) o si no con paisanos. Sin embargo, no se dan entre ellos apenas otro tipo de modelos que son muy recurrentes, por ejemplo, en el caso de las nacionalidades africanas, que se tienden a compartir piso incluso con desconocidos de diferentes nacionalidades ${ }^{25}$. Se diría que las (incipientes) redes bolivianas están comenzando a funcionar ${ }^{26}$, aunque como se verá posteriormente existe un sentimiento fuerte de transitoriedad en el proyecto migratorio.

Gráfico 7. Con QuiÉn EMIGRÓ, QUiÉNES DE SUS FAMILIARES HAN EMIGRAdo y CUÁL FUE EL PRIMER DESTINO PREFERIDO.
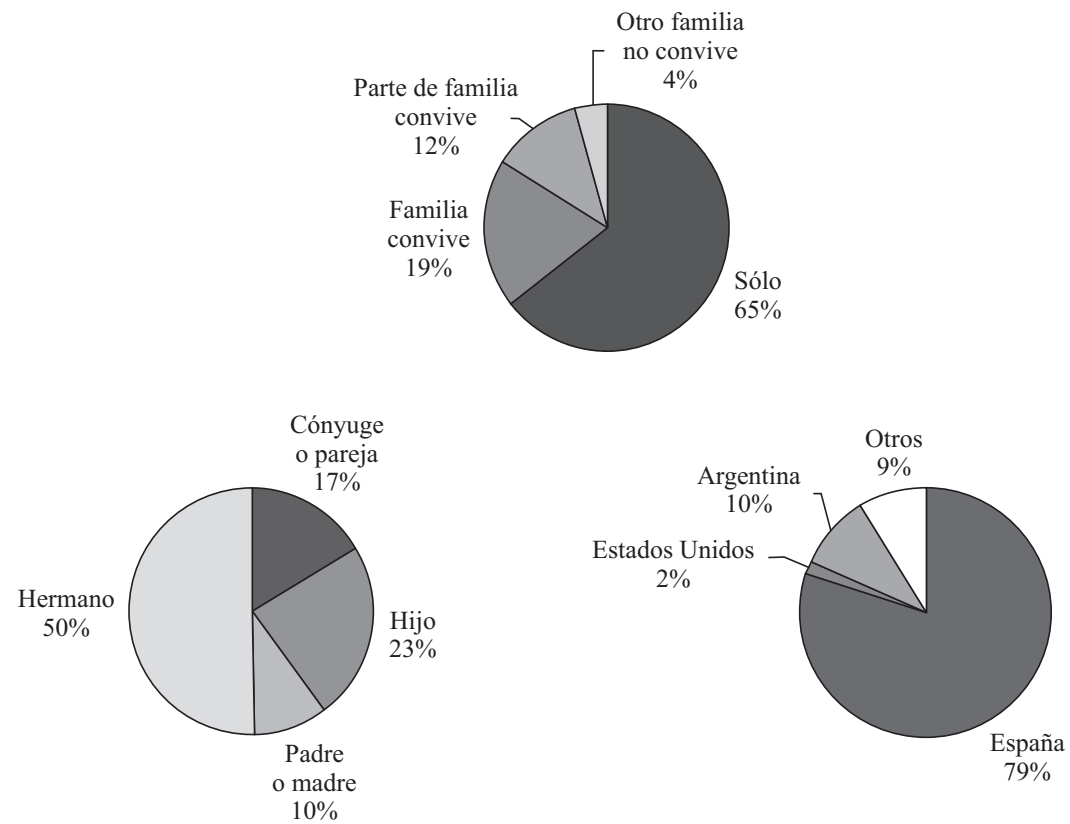

Fuente: Elaboración propia a partir de los microdatos de la ENI.

25 IOÉ, 2005.

26 En un reciente monográfico sobre este colectivo, próximo a ver la luz, dirigido por la autora, se percibe tan fuertemente el recurso étnico-familiar que parece existir una «burbuja boliviana» que se mueve en los distintos ámbitos de la sociedad española mitigando posibles contactos individuales con ésta. Esta cuestión debe ser motivo de investigaciones futuras. 
Cuando se analiza la trayectoria migratoria de los bolivianos encuestados llaman tres cosas la atención: que la migración la lleva a cabo un pionero; que existe una reciente pero arraigada tradición migratoria de jóvenes trabajadores; y que esa tradición migratoria es hacia España. Los gráficos siguientes pueden iluminar estas afirmaciones.

En cuanto a la primera afirmación, el inicio de la aventura, nótese cómo en la gran mayoría de los casos $(65 \%)$ el viaje se ha emprendido solo (aunque un tercio declara haber viajado con toda o parte de la familia). Se trata además de un pionero con un proyecto incierto, casi un cuarto de los encuestados declaraba querer regresar; casi un quinto no tenía una idea clara y el resto pensaba permanecer entre nosotros. Esta incertidumbre ha sido también constatada en otras investigaciones ${ }^{27}$. La segunda cuestión se refiere a la trayectoria migratoria de los parientes y se escenifica en el gráfico de la derecha: la gran mayoría de los familiares del encuestado que emigran son los hermanos; ello es lo que nos permite afirmar que se trata de una migración de coetáneos, no de reagrupados (pues en ese caso se hablaría de padres, cónyuges o hijos), aunque posteriormente esta migración de reagrupados pueda o vaya a darse. Por fin el tercer dato relevante es que la gran mayoría, cercana al $80 \%$, de los encuestados declaró tener como primer destino preferido nuestro país, muy lejos de los tradicionales destinos de la migración boliviana que antes se han mencionado. Los motivos que declaran para acudir a España corroboran la hipótesis de la migración inicialmente transitoria que se ha venido comentando: en su mayoría se trata de encontrar o mejorar el empleo, $60 \%$ de los casos, muy lejos quedan los aspectos de la reagrupación familiar, un $22 \%$, o adquirir formación un $9 \%$.

El despegue económico de España junto con la no exigencia de visado para entrar en el país junto con la crisis sostenida (caso de Argentina) o las dificultades en el acceso (caso de Estados Unidos) en destinos tradicionales de emigración boliviana. Por lo tanto, el patrón migratorio boliviano se describe a partir de un único y joven pionero ${ }^{28}$ indeciso en cuanto a su futuro. Lo cual no implica que la familia y los amigos (en definitiva las redes fuertes y cercanas) no hayan tenido influencia en la decisión de emigrar o en el desarrollo ulterior de este proceso. De entrada son esa familia y estos amigos que ya han emigra-

27 El trabajo inédito al que anteriormente se aludió en estas páginas.

28 Más bien debería hablarse de pionera: el colectivo boliviano en España es el más feminizado de todos los pertenecientes a países en desarrollo, con un 56\% de mujeres según los datos del último padrón municipal. En el caso de la ENI, el 65\% de los encuestados fueron mujeres. En el reciente análisis elaborado por Crane Draper, 2008: 254, se calculaba que 21.000 mujeres habían abandonado el país en los dos últimos meses de 2006. 
do quienes más presentes están (en un $76 \%$ de los casos encuestados) en la toma de la decisión de venir.

Además, los migrantes tienen, en su mayoría, a quien dirigirse cuando llegan a España (un $82 \%$ así lo afirma), principalmente la familia (75\% de los casos), y luego los amigos (25\%). Para sufragar el coste del viaje, alrededor de los 2.500 euros, casi la mitad poseían el dinero (esto es interesante porque puede ser indicativo de que la decisión de emigrar se ha tomado con la antelación y la racionalidad suficientes para ir ahorrando); al resto se lo han financiado fundamentalmente prestamistas $(60 \%)$ o bancos $(23 \%)$ aunque la familia también contribuye en el $12 \%$ de los casos. La familia es también muy importante en el caso de conseguir un empleo ${ }^{29}$, son los amigos y parientes quienes, en el $72 \%$ de los casos, han intervenido positivamente; muy lejos de otras instancias como el recurso a anuncios y ofertas (8\%), la solicitud directa al empresario $(7 \%)$ o la ayuda de alguna ONG (8\%).

En cuanto al contacto con Bolivia, mantenido prácticamente por el total de los encuestados, es básicamente telefónico (para toda la muestra) o virtual (chat o correo electrónico, para un tercio de la misma), con una periodicidad semanal. Cuestión distinta es el acercamiento físico: el $75 \%$ de los encuestados no han regresado a Bolivia. Lógico podría parecer esto en tanto en cuanto prácticamente dos tercios de los bolivianos llevan menos de tres años en nuestro país; son, de hecho, quienes más tiempo llevan los que han viajado, aunque en pocas ocasiones. El motivo más aducido son las vacaciones o las visitas a la familia; no los papeles (y menos será éste un motivo desde el cierre de fronteras acaecido en 2007).

\section{Remesas e inversión transnacional: algunos de sus factores determinantes}

Prácticamente dos tercios de los encuestados envían remesas a su país con una periodicidad en su mayor parte mensual, siendo el monto aproximado de 2.200 euros $^{30}$ anuales y la vía mayoritaria las remesadoras (60\%) seguidas de

29 Aunque ya se intuye, en el caso de España es aún temprano para ver cómo van a actuar las redes bolivianas. Sí existen estudios referidos al funcionamiento de las redes laborales en Argentina: Dos ejemplos: Por un lado, han ocasionado el desplazamiento de trabajadoras desde el servicio doméstico al sector textil en Buenos Aires. Bastia, 2007. Por otro, las actividades transnacionales familiares bolivianas han sido las responsables de la transformación del área de la horticultura periurbana de la ciudad de Río Cuarto en la provincia de Córdoba. Benencia y Geymonat, 2005.

30 Este importe se corrobora con el calculado por el Fondo Multilateral de Inversión en reciente estudio referido a las remesas enviadas por los latinoamericanos desde España. En la misma línea, el mencionado informe del CEBEC, cifra en el $82 \%$ el número de bolivianos residentes que, desde España, envían dinero a Bolivia. 
los bancos. En cuanto al destinatario de los envíos, los más frecuentes son los padres (un 54\% de los remitentes les destina transacciones) seguidos de los hijos (38\% de los remitentes); resulta, sin embargo, curioso el hecho de que el cónyuge o pareja tan sólo sea mencionado como receptor para un $10 \%$ de los remitentes. Un posible motivo de este comportamiento es que, en el caso de parejas con hijos, el esposo se encuentre también en España y que el dinero se envíe a miembros del resto de la familia. Otra posibilidad puede venir dada por el hecho de que la mayor parte de los emisores de remesas sean mujeres, se encuentren en difícil situación de pareja ocasionada por la migración y estén canalizando los envíos para su prole directamente o a través de otros familiares. Este tipo de situaciones parecen estar sucediendo desgraciadamente según se deduce de recientes estudios monográficos sobre la situación de la familia en Bolivia ${ }^{31}$.

Gráfico 8. Remesas, SEXo, PASO DEL tiEMPO y PROYeCto Migratorio.

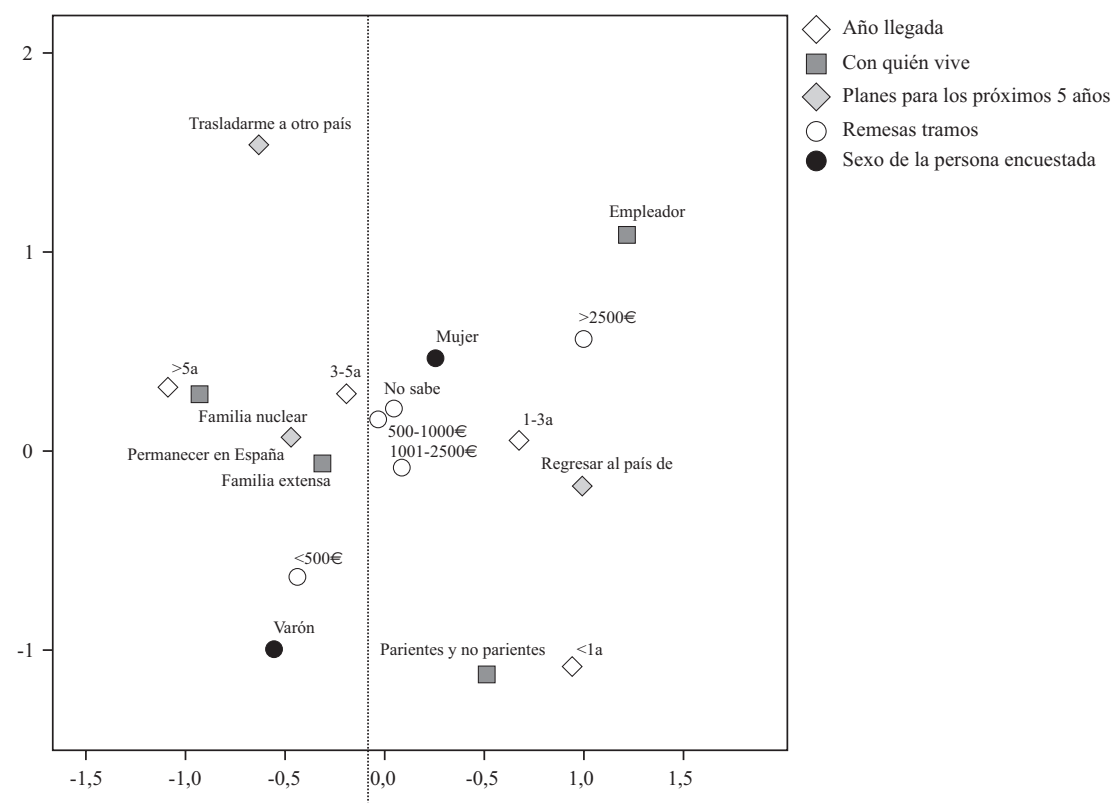

Fuente: Elaboración propia a partir de los microdatos de la ENI.

31 ACOBE, 2007. Crane Draper, 2008. 
Algunas conclusiones pueden deducirse del análisis simultáneo de ciertas variables que vienen considerándose determinantes para el envío de las remesas o la cantidad enviada. Así se ha contemplado la antigüedad en España y, unida a ésta, la situación familiar del encuestado. Adicionalmente se han considerado el sexo y los planes a medio plazo de los migrantes.

Lo primero que destaca, así, es el diferente comportamiento de varones y mujeres, las primeras viven en peores circunstancias, más dependientes del empleador y por ello sus ingresos son menores; sin embargo esta situación de desarraigo les lleva a ahorrar y, por ende, a enviar unas cantidades mayores a su familia: más de la cuarta parte de las mujeres enviaba más de 2.500 euros anuales a casa; en el caso de los hombres este monto apenas lo alcanza el $19 \%{ }^{32}$.

Por otra parte, debe destacarse la relación inversa que tiene lugar entre el paso del tiempo y las cantidades enviadas: de los que llevan menos de un año en España, casi la mitad envía al año más de 1.000 euros; mientras que es esa misma cantidad apenas es enviada por un tercio de los que llevan en España más de cinco años. Claro que esta cuestión va unida a la situación familiar que, ya se trató anteriormente, se estabiliza con el tiempo. A una mayor estabilidad familiar, menor estabilidad en los flujos de remesas: el $40 \%$ de los individuos residentes en el domicilio del empleador enviaba más de 2.500 euros anuales; de los que vivían con la familia consanguínea esta cantidad era tan sólo enviada por el $13 \%$.

Un último dato, la constatable relación entre la intención de permanecer en España y el descenso entre las cantidades enviadas. Así, son mucho mayores las cantidades que desean enviar y que envían aquellos con un proyecto migratorio provisional; que, por cierto, se identifica con las situaciones interinas que atraviesan las migrantes bolivianas. Sin embargo, aquellos que tienen una mayor estabilidad familiar en España se identifican con un proyecto de más largo plazo y automáticamente el monto de los envíos desciende.

En fin, si se analiza la relación existente entre la región de procedencia y las cantidades enviadas, se detectan diferencias en el comportamiento.

De entrada, un 38\% de los remitentes de remesas son de Cochabamba, un $14 \%$ de La Paz y el 48\% de Santa Cruz. Además, los de Cochabamba, siempre en peor situación, son quienes, con un proyecto migratorio de menor calado,

32 Ya se ha hablado de las pioneras bolivianas. A falta de ulteriores investigaciones, los conocimientos actuales sobre el tema permiten afirmar que la mujer inicia la migración en condiciones de interinidad y paulatinamente traerá a su familia, en el caso de que su proyecto migratorio devenga definitivo. Este hecho también explicaría el que los hombres bolivianos presenten unas pautas más asentadas en lo que se refiere a sus condiciones del hábitat. 
GrÁFICO 9. REMESAS, PROVINCIA DE ORIGEN Y PROYECTO MIGRATORIO.

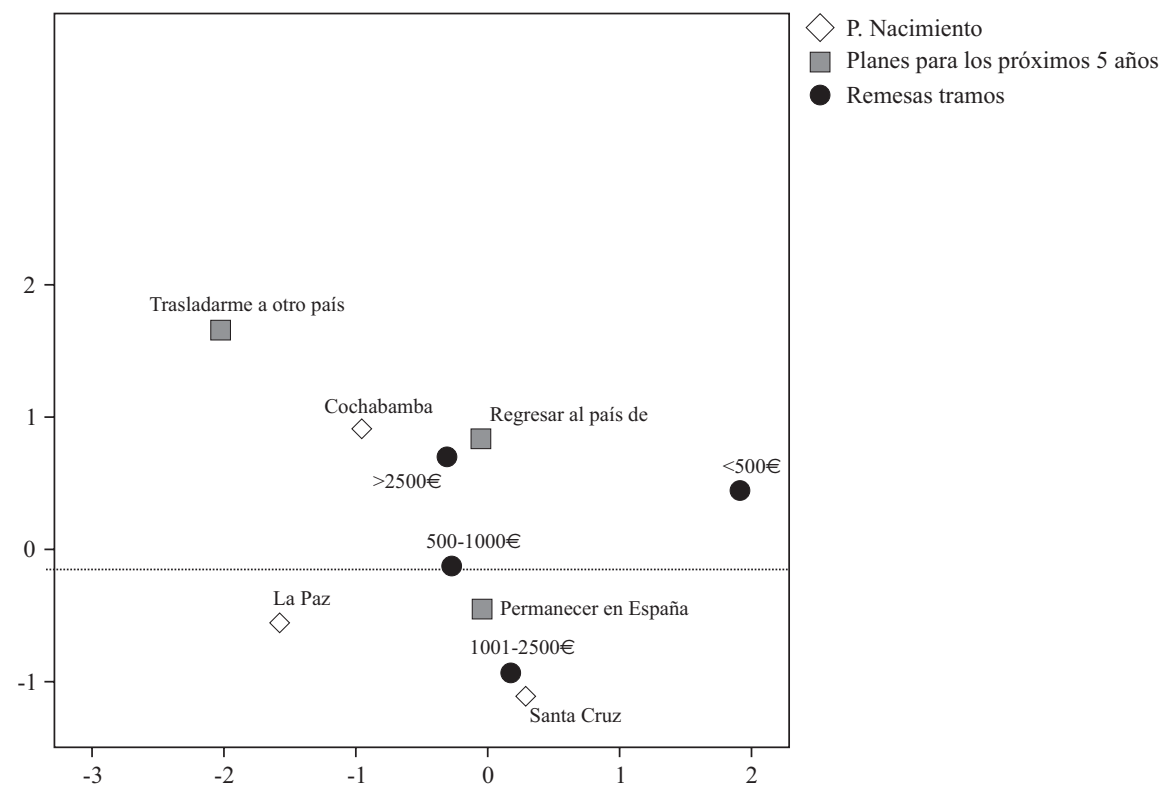

Fuente: Elaboración propia a partir de los microdatos de la ENI.

se revelarían como los remitentes de mayor importancia: envían una media de 2.300 euros anuales. Mayor intención de quedarse tendrían los de La Paz y Santa Cruz traduciéndose ello en los flujos: si bien en el caso de los paceños la media de remesas enviadas es muy elevada, 3.500 euros, debe tenerse en cuenta que los procedentes de este lugar son los menos representativos entre los emisores de remesas.

Por último, destaca el caso de los de Santa Cruz, que suponen el 48\% de los remitentes encuestados; sin embargo, los flujos que envían, en una medida de 1.900 euros anuales, resultan ser proporcionalmente menores (de hecho, casi el 40\% de los santacruceños está enviando menos de 1.000 euros al año).

\section{La (inexistente) inversión transnacional}

La tabla muestra de manera sinóptica el porcentaje de individuos que mantiene vinculaciones de trascendencia económica — aparte de las remesascon su país de origen; que ha tomado acciones de cara su salida del país; y que ha llevado a cabo inversiones en España. 
Tabla 1. Relaciones eCONÓMicAs CON El LUGar de ORIGen.

\begin{tabular}{|l|c|c|c|}
\hline \multirow{2}{*}{} & \multicolumn{2}{|c|}{ Bolivia } & España \\
\cline { 2 - 4 } & Es propietario & Al migrar vendió & Invirtió en \\
\hline Vivienda & $25 \%$ & $3 \%$ & $7 \%$ \\
Tierras & $9 \%$ & $1 \%$ & $0,5 \%$ \\
Ganado & $2 \%$ & $1 \%$ & \\
Negocio & $2 \%$ & $5 \%$ & $0,5 \%$ \\
Automóvil & $2 \%$ & $6 \%$ & $2 \%$ \\
préstamos a otros & & & \\
\hline
\end{tabular}

Fuente: Elaboración propia a partir de los microdatos de la ENI.

Las cifras hablan por sí solas y hacen pensar que los encuestados poco tienen que dejar en su tierra natal y poco, de momento, han aventurado en nuestro entorno. Destacaría, si acaso, el escaso número de propietarios que vendieron su casa, lo cual corroboraría la transitoriedad del proyecto migratorio que venimos describiendo. Y también el tímido acercamiento a la inversión inmobiliaria en una España que a fecha de hoy aparece llena de incertidumbres en el panorama económico.

\section{A MODO DE CONCLUSIÓN}

El mercado de trabajo se encuentra sectorialmente fragmentado, tanto en el caso de Bolivia como en el de España, aunque en Bolivia resulta además determinante el nivel de estudios, encontrándose ello vinculado con la región de procedencia: la mayor calidad de los trabajos y los salarios se da en la región de La Paz y la menor en Cochabamba. En España, la segmentación laboral se da principalmente en función del sector y del sexo. Los trabajadores bolivianos experimentan una desvalorización profesional patente en España, marcada por el desempeño de trabajos de cualificación media o media baja en la gran mayoría de las ocasiones. El capital humano (aunque desvalorizado) resulta exportable en supuestos como la construcción o ciertos subsegmentos de los servicios. No así en otros casos que recaban en el servicio doméstico. Aunque con diferencias relativamente pequeñas, de nuevo son los paceños los que mejor parecen desenvolverse.

El paso del tiempo determinaría la movilidad laboral ascendente, marcando la asociación entre salarios más elevados con períodos largos de estancia en España. Sin embargo, aunque se detecta cierta relación entre elevados niveles de capital humano y mejores salarios, dicha relación es más débil debido a que 
los diferentes niveles de capital humano se han ido incorporando progresivamente y se ve influida por el escaso tiempo transcurrido desde la llegada. Las pautas de uso del hábitat para los bolivianos vienen determinadas por su situación laboral y familiar. No obstante, se observa una tendencia clara en este colectivo a compartir su vivienda con consanguíneos en primera instancia. Si no fuera posible, lo hacen con la familia extensa o con paisanos, sin que se dé apenas la circunstancia de compartir vivienda con individuos de otros colectivos. Existe, sin embargo, un elevadísimo porcentaje de personas (principalmente mujeres) que habitan en el domicilio del empleador; se trata de las pioneras en la cadena migratoria. Por regiones de origen, la mayor precariedad residencial se detecta entre los de Cochabamba, existiendo entre los paceños el mayor número de propietarios.

El régimen de tenencia de la vivienda está íntimamente unido a la situación familiar de cada uno y al paso del tiempo. Aunque la mayor parte de los encuestados se ve forzado a vivir en régimen de alquiler, se da un mayor número de propietarios entre los que llevan más tiempo en España y viven con la familia nuclear. Son los que viven en el domicilio del empleador quienes menor tiempo llevan entre nosotros. Una forma de tenencia relativamente habitual entre aquellos más asentados es el hecho de habitar en una vivienda cedida por otro familiar: ello puede ser una seña del funcionamiento incipiente de las redes bolivianas en nuestro país.

Las actividades transnacionales llevadas a cabo por el colectivo boliviano presentan, a fecha de hoy, ciertos indicios de debilidad o, al menos, se encuentran desdibujadas. Los bolivianos mantienen contacto semanal con su casa, telefónico o por vía cibernética, aunque muy pocos han visitado de nuevo su país (bien es cierto que llevan entre nosotros muy poco tiempo). Aparte de ello, no se detectan, de momento, conexiones de índole económica. Pocos poseen vivienda en propiedad en su lugar de origen y pocos han iniciado inversiones en España; si bien en este último caso existe una fuerte relación positiva entre la inversión en vivienda y el tiempo de estancia en nuestro país. Las actividades empresariales son inexistentes. Todo ello nos ilumina acerca de la incertidumbre del proyecto migratorio boliviano.

La mayor parte de los bolivianos envía remesas a su país, aunque se detecta una relación inversa entre el monto de las mismas, su intención al migrar y el grado de asentamiento en España. De hecho las cantidades más importantes son remitidas por los que llevan menos tiempo, presentan unas condiciones de vida más precarias y, por ello, no se han asentado aún familiarmente. Es, además, diferente el comportamiento atendiendo a la región de procedencia en Bolivia. Los cochabambinos resultan los más involucrados en este ámbito, mientras que la menor propensión a remitir parece mostrarla los paceños. 
En definitiva, se ha explorado la situación de un colectivo con un proyecto migratorio incierto que se encuentra en fase de asentamiento, no situado aún en un mercado laboral que responda a sus cualificaciones (algo que tardará mucho en darse dada la crisis actual que afecta sobre todo a población inmigrante), con redes frágiles aunque ya comenzando a funcionar y, fuera de las remesas, con débiles atisbos en su dimensión transnacional.

\section{BIBLIOGRAFÍA}

Acobe (Asociación de Cooperación Bolivia España), Situación de familias de migrantes a España en Bolivia, Madrid, Acobe, 2008.

Argerey, Patricia, Estévez, Lucana, Fernández, Mercedes y Menéndez, Eva, El fenómeno de la inmigración en Europa. Perspectivas jurídicas y económicas, Madrid, Dykinson, 2005.

Banco de España. Balanza de pagos y posición internacional de España 2007. http://www.bde.es/informes/be/balpag/2007/bp2007.pdf

Basch, Linda, Glick Schiller, Nina y Szanton Blanc, Cristina, Nations Unbound: Transnational Projects, Postcolonial Predicaments, and the Deterritorialized Nation-State, Nueva York Gordon and Breach, 1994.

Bastia, Tanja, «From Mining to Garment Workshops: Bolivian Migrants in Buenos Aires», Journal of Ethnic and Migration Studies, 33-4 (Sussex, 2007): 655-669.

Benencia, Roberto y Geymonat, Marcela, «Migración transnacional y redes sociales en la creación de territorios productivos en la Argentina. Río Cuarto, Córdoba.» Cuadernos de desarrollo rural, 55 (Bogotá, 2005): 9-28.

Borkert, Maren, Bosswic, Wolfgang, Heckmann Friedrich y Lüken-Klaßen, Doris, Local integration policies for migrants in Europe European, Dublín, European Foundation for the Improvement of Living and Working Conditions, 2007.

Bourdieu, Pierre y Wacquant, Loïc, An invitation to reflexive sociology, Chicago, University of Chicago Press, 1992.

Cachón Rodríguez, Lorenzo, «Integración de los inmigrantes a través del trabajo», Documentación social, 132 (Madrid, 2004): 97-120.

Centro Boliviano de Economía (CEBEC), Migración, aspectos sociales y económicos, Santa Cruz, CEBEC/CAINCO, 2007.

Colectivo IOÉ, Inmigración y vivienda en España, Madrid, Ministerio de Trabajo e Inmigración, 2005.

Crane Draper, Melissa, «Trabajadoras, líderes y madres: las mujeres bolivianas en un mundo globalizado», Jim Shultz y Melissa Crane Draper (eds.), Desafiando la glo- 
balización. Historias de la experiencia boliviana, La Paz, El Centro para la Democracia-Plural editores, 2008: 237-278.

Faist, Thomas, The Volume and Dynamics of International Migration and Transnational Social Spaces. Oxford, Clarendon Press, 2000.

Fernández García, Mercedes (dir.), Estudio sobre la situación de la inmigración boliviana en España, Madrid, Observatorio Permanente de la Inmigración, Ministerio de Trabajo e Inmigración, 2008.

Greenacre, Michael, La práctica del análisis de correspondencias, Madrid, Fundación BBVA, 2008.

Heckmann, Friedrich, Integration Policies in Europe: National Difference or Convergence?, EFMS Paper N. ${ }^{\circ} 33,1999$.

Instituto Nacional de Estadística (INE). Encuesta Nacional de Inmigrantes (ENI), Madrid, 2008.

Kearney, Michael, «From the Invisible Hand to Visible Feet: Anthropological Studies of Migration and Development», Annual Review of Anthropology, 15 (Palo Alto, California, 1986): 331-361.

Pennix, Rinus y Martinielo, Marco, «Integration Processes and Policies: State of the Art and Lessons», Rinus Pennix, Karen Kraal, Marco Martiniello y Steven Vertovec (eds.), Citizenship in European Cities: Immigrants, Local Politics, and Integration Policies, Hampshire, Ashgate Publishing, 2004: 139-164.

Massey, Douglas, Joaquín Arango, Hugo Graeme, Ali Kouaouci, Adela Pellegrino y Edward J. Taylor, Worlds in Motion: Understanding International Migration at the End of the Millennium, Oxford, Clarendon Press, 1998.

Mincer, Jacob, Schooling, Experience and Earning, Nueva York, National Bureau of Economic Research, 1974.

Piore, Michael, «La importancia de la teoría del capital humano para la economía del trabajo; un punto de vista disidente», Luis Toharia (comp.), El mercado de trabajo: Teorías y aplicaciones. Madrid, Alianza Universidad Textos, 1983: 105-114.

Portes, Alejandro, «Immigration and the Metropolis: Reflections on Urban History», Journal of International Migration and Integration, 1 (Edmonton, 2000): 153-175.

Sassen, Saskia, La Ciudad Global: Nueva York, Londres, Tokio. Buenos Aires, Eudeba, 1999.

Schultz, Theodore, «Investment in Human Capital», The American Economic Review, 51-1 (Pittsburgh, PA, 1961): 1-17.

Tornos, Andrés, Rosa Aparicio y Mercedes Fernández, El capital humano de la inmigración, Madrid, Ministerio de Trabajo y Asuntos Sociales, 2004. 
Vertovec, Steve, «Migration and Other Modes of Transnationalism: Towards Conceptual Cross-Fertilization», International Migration Review, 37-3 (Nueva York, 2003): 641-665.

Whitesell, Lily, «Y aquellos que se fueron: retratos del éxodo boliviano», Jim Shultz y Melissa Crane Draper (eds.), Desafiando la globalización. Historias de la experiencia boliviana, La Paz, El Centro para la Democracia-Plural editores, 2008: 279-317.

\section{BOLIVIANS IN SPAIN}

This paper aims to analyse the behaviour of the Bolivian community in Spain, based on microdata from the National Survey of Immigrants. Starting from socioeconomic integration parameters as well as theoretical postulates on human resources, segmented labour market and transnational views on migration, and using the factorial analyses of multiple correspondences, this paper suggests an outline of Bolivians living currently in Spain.

KEY WORDS: Bolivian community, socioeconomic integration, segmented labour market, exportability of human resources, transnationalism. 